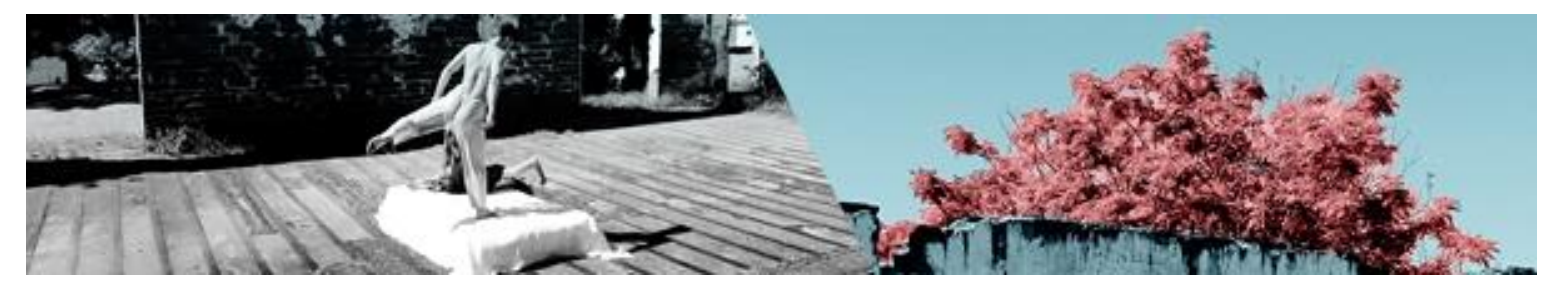

\title{
REFLEXÕES SOBRE A DISCIPLINA DE ESTÁGIO CURRICULAR OBRIGATÓRIO I E II DO CURSO DE LICENCIATURA EM DANÇA DA UFG
}

\author{
Valéria Maria Chaves de Figueiredo ${ }^{1}$ \\ Warla Giany Paiva ${ }^{2}$
}

\begin{abstract}
Resumo: Este trabalho busca apresentar um panorama da implementação da disciplina Estágio Curricular Obrigatório I e II, do curso de licenciatura em dança da Universidade Federal de Goiás - UFG, ministrada no primeiro semestre de cada ano aos estudantes do $5^{\circ}$ e 6ํㅜ períodos. Busca-se com isso apontar e tecer reflexões relativas às várias transformações ocorridas ao longo da disciplina no que concerne sua estrutura e organização, bem como, as mudanças significativas que a sua implementação dinâmica tem provocado nos campos de estágio. As atividades da disciplina iniciaram em 2013. Os estágios I e II acontecem em um mesmo campo de estágio, no qual o primeiro momento é voltado para a investigação em torno dos aspectos que compõem a gestão escolar, projeto político pedagógico, currículo e as teorias pedagógicas. E o segundo momento, aos estudos sobre propostas pedagógicas para o ensino de dança em ambiente escolar com ênfase na regência. No decorrer desse processo observamos mudanças nos campos de estágio e na própria instituição formadora, revelando uma complexa trama política, educacional e social. Esta teia de tensões propiciou o desejo e a necessidade de uma reflexão mais sistemática da disciplina objetivando acompanhá-la em seus primeiros anos de implementação, levantando as potencialidades e os aspectos desafiantes e problematizadores. Utilizamos como referencial teórico, estudos de Paulo Freire, Demerval Saviani, Ilma Passos, Marli André, Karenine Porpino, entre outros.
\end{abstract}

Palavras-chave: Estágio; Ensino de Dança; Escola.

\section{REFLECTIONS ON THE MANDATORY CURRICULAR STAGE DISCIPLINE I AND II OF THE DANCING LICENSE IN THE UFG}

\begin{abstract}
This study aims to present an overview of the implementation of discipline Mandatory Curricular Internship I and II, the degree course in dance at the Federal University of Goiás - UFG, it is given in the first half of each year to students of 5th and 6th periods. Search yourself with this point and weave reflections on the various transformations over the course regarding its structure and organization as well as the significant changes that the dynamic implementation of it has caused in the internship fields. The activities of the discipline in the course of dance, started in 2013. Stage I and II take place in the same training field, in which, the first time focusing on research around the aspects that make up the school management, pedagogical political project, curriculum and pedagogical theories. And the second time

\footnotetext{
${ }^{1}$ Valéria Maria Chaves de Figueiredo - Professora associada da Universidade Federal de Goiás. Atua nos cursos de Dança e Teatro. Doutora em educação pela Unicamp. Mestre em Artes pela Unicamp. Coordenadora de estagio e do Pibid do curso de Dança. Pesquisadora nas áreas de história e memória e corpo, escola e educação.

2 Warla Giany de Paiva - Artista performer, professora e pesquisadora do movimento e da dança. Atua no Centro de Estudo e Pesquisa do Ciranda da Arte - Seduc/Go. Mestre em Performances Culturais pela Universidade Federal de Goiás (2015). Especialista em Pedagogias da Dança pelo CEAFI/PUC - GOIÁS.
}

FIGUEIREDO, Valéria Maria Chaves de; PAIVA, Warla Giany. Reflexões sobre a disciplina de estágio curricular obrigatório I e II do curso de licenciatura em dança da UFG.

Revista da FUNDARTE, Montenegro, p.54-71, ano 19, no 37, Janeiro/Março.

Disponível em: http://.seer.fundarte.rs.gov.br/index.php/RevistadaFundarte/index> 30 de março de 2019. 


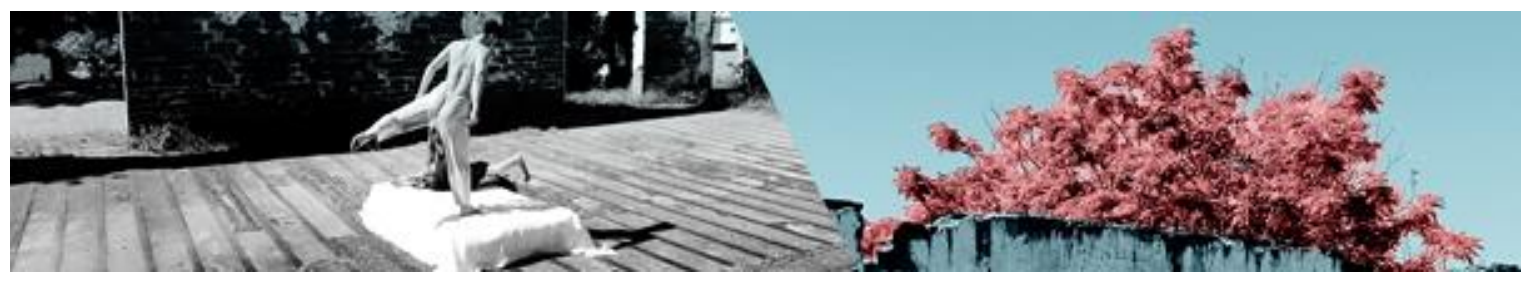

studies on pedagogical proposals for dance education in school environment with an emphasis on teaching. In the process we observe changes in training camps and in their own educational institution, revealing a complex plot political, educational and social. This web of tensions led to the desire and the need for a more systematic reflection of discipline aiming to accompany her in her early years of implementation raising the potential, the challenging aspects and problem-solving. The theoretical framework study of Paulo Freire, Demerval Saviani, Ilma Passos, Marli André, Karenine Porpino, among others.

Keywords: Internship; Dance Teaching; School.

Nesse artigo pretendemos descortinar e debater aspectos do ensino de dança que atravessam suas proposituras metodológicas, para em um segundo momento apresentar e refletir sobre os processos de implementação referente à estrutura e organização das disciplinas de Estágio Curricular Obrigatório I e I| do Curso de licenciatura em Dança da Faculdade de Educação Física e Dança da Universidade Federal de Goiás - UFG. Também queremos apresentar alguns pontos de tensão, conflitos e reflexões que se apresentam nesses processos de implementação dos estágios em um curso de licenciatura em dança.

Quando pensamos em dança na escola, as imagens se manifestam e ressaltam a sua presença nas festas tradicionais da instituição, nos espaços de lazer e recreação, nos vídeos do youtube, nas crianças pequeninas que ao ouvir uma música se movem divertidamente, etc. $\mathrm{Na}$ escola e na universidade essa presença é motivadora, mas ao mesmo tempo deslegitimadora de saberes que preenchem e esvaziam essa área de conhecimentos tão importante para a formação humana. Muitos desencontros e confrontos compõem o espectro da dança na escola hoje.

O que percebemos, portanto, é que a dança de alguma forma faz parte do cotidiano escolar, principalmente após a nova LDB, depois com os PCNs e a nova expectativa com a Base Nacional Curricular Comum - BNCC. Sabemos que o calendário escolar possibilita muitos espaços para atividades artísticas e interdisciplinares, mas muitas vezes são ocupados por projetos isolados e não projetos coletivos e instigantes. O que fazer? Como fazer? Onde e quando fazer? Como atuar e melhorar as compreensões em torno da educação e do ensino de dança na escola de modo a ampliar a sua contribuição e legitimar seu espaço no ensino formal?

FIGUEIREDO, Valéria Maria Chaves de; PAIVA, Warla Giany. Reflexões sobre a disciplina de estágio curricular obrigatório I e II do curso de licenciatura em dança da UFG.

Revista da FUNDARTE, Montenegro, p.54-71, ano 19, no 37, Janeiro/Março.

Disponível em: http://.seer.fundarte.rs.gov.br/index.php/RevistadaFundarte/index> 30 de março de 2019. 


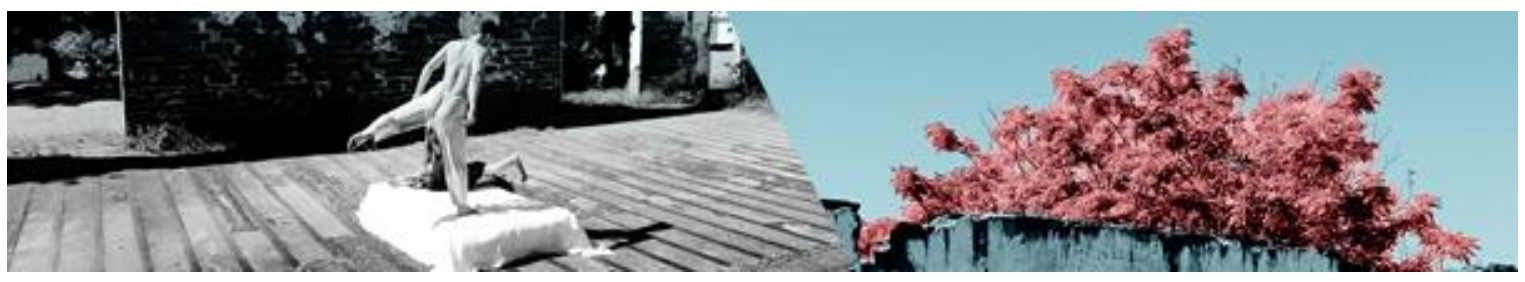

Abrir brechas e possíveis caminhos é nossa intenção aqui, considerando que diálogos e conflitos preenchem e distendem as visões, na arte é necessário esse lugar de confronto com as racionalidades e as dicotomias, para se criar a oportunidade de se estabelecer outras redes de conhecimento e crescimento intelectual, social, cultural, físico e emocional. Busca-se com isso revisitar essa perspectiva dicotômica que nos atravessa historicamente para o alargamento de nossas percepções em relação à mercantilização da experiência, provocando assim, outras formas de (re)existir e de re(fletir).

O mundo moderno trata de associar valores mercantis e de consumo, hierarquizando saberes, diluindo sensibilidades e singularidades, desqualificando o outro, destituindo as diferenças. Esta perversa rede produz exclusão, violência, alimenta conformidades e apatias. Como recuperar capacidades de deixar rastros e marcas? Na impossibilidade de esgotar a discussão, propomos articular questões, afim se constituir alternativas e experiências outras de convício com a dança e a comunidade escolar tendo como eixo a produção de saberes artísticos, estéticos, históricos, educativos, ancorados na possibilidade de transformação.

Portanto, ainda é urgente a problemática entre teoria e prática no âmbito da dança na escola. Metodologias que reforçam as dicotomias estão presentes ainda no ambiente escolar e, principalmente, nas aulas de dança, portanto são necessárias e urgentes de serem problematizadas, merecendo novas discussões e reflexões. Pode-se dizer que ainda há uma espécie de litígio entre a dança e os espaços escolares, que alimenta tensões e dificulta muitas superações necessárias.

Essas oposições entre teoria e prática no campo da dança ainda nos provocam que se superem os conservadorismos históricos, tão presentes na área. Ainda é bastante difícil compreender pedagogicamente como as escolas de dança, por exemplo, oferecem aulas de técnica, na maioria balé, em projetos de contraturno em escolas privadas e simplesmente como atividade física, na maioria das vezes. Buscar compreender a dança no âmbito da escola implica em um exercício de "re-fletir". "Refletir" vem do verbo "reflectere" que significa voltar atrás. É um repensar, um

FIGUEIREDO, Valéria Maria Chaves de; PAIVA, Warla Giany. Reflexões sobre a disciplina de estágio curricular obrigatório I e II do curso de licenciatura em dança da UFG.

Revista da FUNDARTE, Montenegro, p.54-71, ano 19, no 37, Janeiro/Março.

Disponível em: http://.seer.fundarte.rs.gov.br/index.php/RevistadaFundarte/index> 30 de março de 2019. 


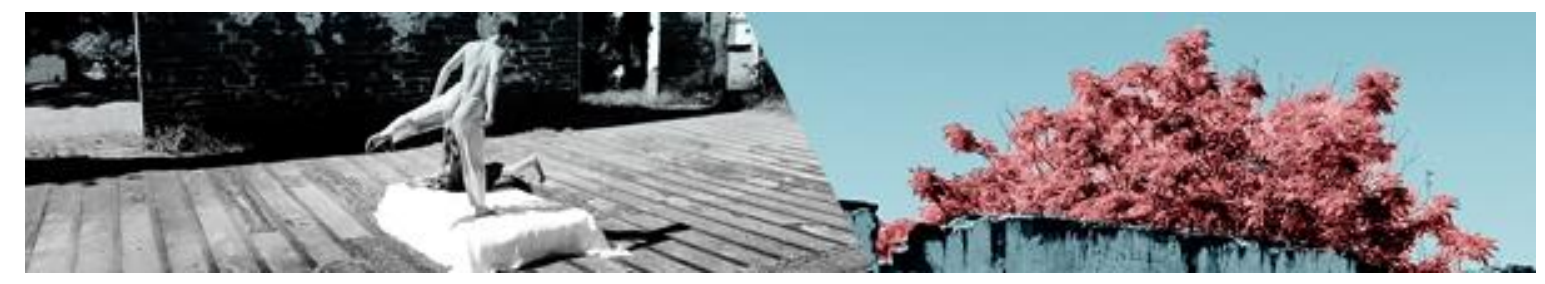

pensamento em segundo grau. Um pensamento consciente de si mesmo, capaz de verificar o grau de adequação que se mantém com os mesmos dados objetivos da realidade (SAVIANI, 1989, p. 23). Então, para ensino de arte, refletir é um movimento sempre fundamental: voltar, rever e, consciente de si mesmo, fazer tentativas de ampliar as leituras do mundo, na perspectiva da humanização, da condição humana e da compreensão das realidades.

Existem princípios importantes que norteiam o ambiente educacional, e refletir sobre a constituição do campo de conhecimento denominado dança e suas relações com o ambiente escolar é falar primeiro de suas características identificatórias, ou seja, aquilo que constitui a área e que está relacionado aos muitos saberes artísticos, científicos, filosóficos, culturais e sociais, que também incluem todas as práticas profissionais que ocorrem fora da escola.

A ideia da abordagem educativa em arte foi bastante estudada por teóricos como John Dewey, Hebert Read, Viktor Lowenfeld e Elliot Einser, e, partindo de seus estudos, foi possível compreender, historicamente, a constituição do campo da arteeducação, a partir do século XX, com suas diferenças e particularidades. $O$ que se verifica, ao longo das últimas décadas, são a ampliação e o crescimento de uma relevância do ensino de arte para a escola, que deixa de ser prática, meramente técnica, e vai se constituindo como conhecimento fundamental na formação humana.

Perguntamo-nos até onde a dança vem rompendo com esses processos de superação de dicotomias entre prática e teoria? De acordo com Osinski (2001), 0 Século XX descobre a criança como ser autônomo, e valoriza, principalmente, a criatividade e a individualidade. Mas o flagrante descompasso entre os estudos realizados cientificamente e o ensino vigente marca ainda a necessidade de outras investigações, que deem conta de uma educação mais criativa, transformadora e crítica e que se contraponha ao sistema unilateral de mera transmissão de conhecimentos técnicos e instrumentais para ensino da arte.

Assim, a partir dos primeiros movimentos de educação artística na educação formal, no início do século XIX, até as primeiras ideias da arte-educação, a partir dos

FIGUEIREDO, Valéria Maria Chaves de; PAIVA, Warla Giany. Reflexões sobre a disciplina de estágio curricular obrigatório I e II do curso de licenciatura em dança da UFG.

Revista da FUNDARTE, Montenegro, p.54-71, ano 19, no 37, Janeiro/Março.

Disponível em: http://.seer.fundarte.rs.gov.br/index.php/RevistadaFundarte/index> 30 de março de 2019. 


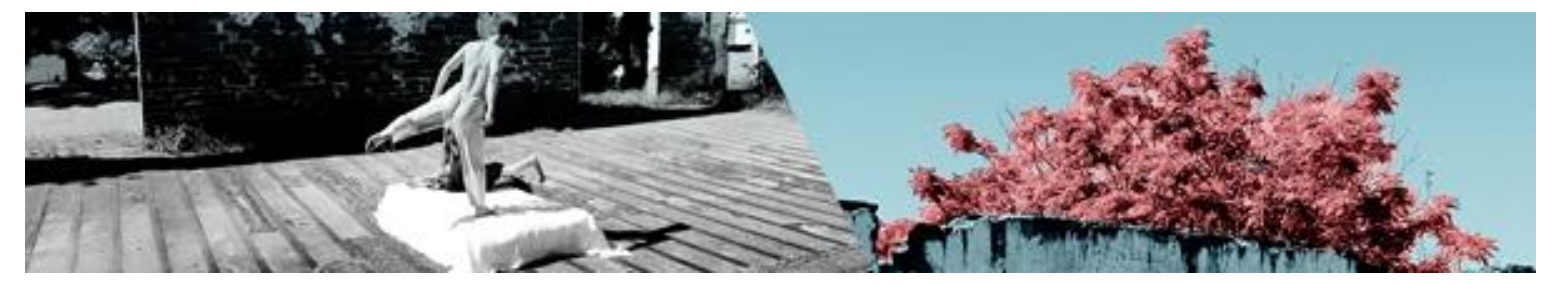

anos 1970, configuram-se importantes batalhas para que a arte na escola desempenhe, de fato, o papel de formadora. De acordo com Ferraz e Fusari (2010), nos últimos anos, - movimento da arte-educação esteve preocupado com a educação escolar, observando e contribuindo para efetivar a presença da arte na lei de diretrizes e bases da educação. Vale lembrar que a lei brasileira № 9394 de 1996 estabeleceu a obrigatoriedade do ensino de arte na educação básica, modificando, finalmente, a relação da arte com a escola pública.

O movimento de arte-educação se iniciou fora da escola, mas esteve ancorado às ideias da "escola nova" e da "educação através da arte". Ferraz e Fusari (2010) discutem que, enquanto o movimento de educação artística esteve preocupado apenas com a expressividade individual e as técnicas, provocando uma lacuna no conhecimento mais aprofundado da arte como lugar formativo, o movimento da arteeducação já buscou novas metodologias de ensino, revalorizando o professor e sua área de conhecimento, além de redimensionar o seu trabalho na escola, incluindo a importância da ação política e sua atuação profissional na sociedade.

Quando pensamos na dança enquanto área de conhecimento e atuante na educação básica, vemos que, de fato, ela está presente nas escolas praticamente durante todo o século XX, entre brechas e resistências. Porém, observamos, também, que velhos problemas permanecem, pois ela ainda representa o lugar das atividades meramente recreativas e/ou das festividades furtivas; a produção artística é encarada como um lugar de divertimento apenas, e não como uma ação educativa. A disciplina de arte, em sua maioria, não contempla dança, e a falta de professores formados aumentam estas distâncias e conflitos com as escolas.

Pensar sobre a dança e suas possibilidades no campo da escola foi nossa prioridade, e percebemos que essas premissas dicotômicas entre o fazer e o pensar, entre a prática e a teoria, entre a técnica e a livre expressão, sugerem ainda uma educação conservadora e, muitas vezes, desconectada da realidade das crianças e dos jovens. Ao considerarmos a dança como prática inclusiva, interdisciplinar e

FIGUEIREDO, Valéria Maria Chaves de; PAIVA, Warla Giany. Reflexões sobre a disciplina de estágio curricular obrigatório I e II do curso de licenciatura em dança da UFG.

Revista da FUNDARTE, Montenegro, p.54-71, ano 19, no 37, Janeiro/Março.

Disponível em: http://.seer.fundarte.rs.gov.br/index.php/RevistadaFundarte/index> 30 de março de 2019. 


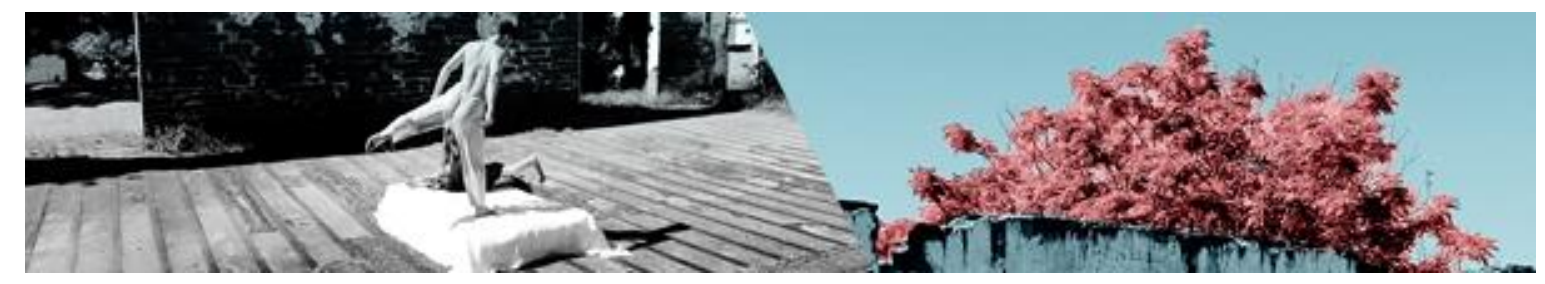

humanizadora, percebemos a importância de se trazer abordagens pedagógicas e metodologias mais significativas, críticas e transformadoras das realidades dos alunos.

Refletir sobre a atualidade e suas dimensões sociais não é tarefa fácil, e é preciso ir além das aparências e das abordagens unilaterais. Um princípio que consideramos, foi de se pensar na dança e no campo da escola como um lugar de múltiplas tessituras, polilógicas redes de comunicação e espaços dialógicos para processos de investigação, com ampla possibilidade de rede entre os saberes. A multiplicidade dos corpos dançantes se dá onde o corpo é expressão e lugar de aprendizagem e de conhecimento.

Já nos anos 1960, o pedagogo Paulo Freire (1987) trazia a educação para o campo da humanização, contrapondo a ideia de instrumentalizar as pessoas para o mercado, valorizando as questões da própria vida e da condição humana. Arroyo (2000) aponta que educar é humanizar e acrescenta que lutar pela humanização, fazernos humano, é a grande tarefa da humanidade e da escola. Este é o sentido do fazer educativo, já que a desumanização é uma realidade histórica. Arroyo (2000) diz também que a sensibilidade de Paulo Freire para enxergar o sujeito, o professor, como alguém que procura, investiga e indaga, desencadeou mudanças importantes nos processos brutais e desumanizantes presentes na educação brasileira, até então. Dentre as suas prioridades, encontra-se a tarefa de ir além da instrumentalização.

Diante desse panorama de primeiros desejos, escolhas, saberes e afetos como (re)significar o estágio na formação de professores de dança nas licenciaturas?

\section{Diferentes lugares para diferentes princípios}

Feliz aquele que transfere o que sabe e aprende o que ensina

Cora Coralina.

Quando e por que se tornou necessário que arte e educação assumam a responsabilidade de estruturar trabalhos e projetos integrados e transdisciplinares na escola? Uma reflexão inicial é a possibilidade de se estabelecer diálogos com a realidade social e cultural que valorize as produções artísticas de cada região e grupos,

FIGUEIREDO, Valéria Maria Chaves de; PAIVA, Warla Giany. Reflexões sobre a disciplina de estágio curricular obrigatório I e II do curso de licenciatura em dança da UFG.

Revista da FUNDARTE, Montenegro, p.54-71, ano 19, no 37, Janeiro/Março.

Disponível em: http://.seer.fundarte.rs.gov.br/index.php/RevistadaFundarte/index> 30 de março de 2019. 


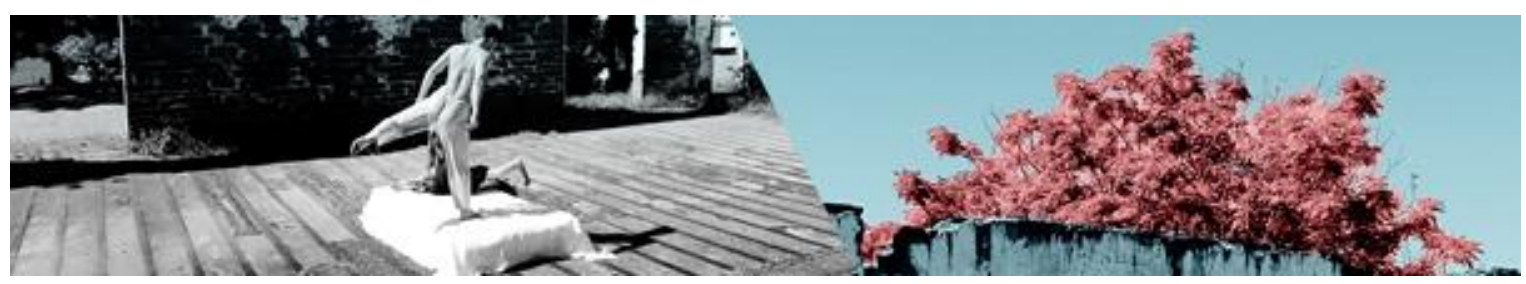

e, ainda, que permita experienciar as relações sociais e culturais a partir das experiências com o corpo e o movimento, compreendendo este corpo enquanto fenômeno histórico, cultural e artístico.

A educação e a escola devem ser integrantes da totalidade social e não meras produções e/ou reproduções da cultura, e cabe à dança desenvolver metodologias, conteúdos e abordagens pedagógicas conectados com a diversidade das realidades sociais no contexto atual. Portanto, fica evidente a importância e a necessidade de um diálogo urgente, nos contextos educacionais, em prol do ensino de uma dança comprometida com a formação humana, de forma crítica e sensível, e que garanta aos alunos conhecer e vivenciar os aspectos das técnicas, das expressividades, percepções, sensibilidades, criatividade, história, memória, novas tecnologias, possibilidades interartísticas e as muitas interações que emergem do fazer artístico.

Nesse sentido, as dicotomias entre práticas e teoria, como as técnicas instrumentalizadoras e funcionais presentes ainda nas aulas de dança, principalmente na escola, intranquilizam e reduzem a possibilidade de superação e transformação. Ações inovadoras e inventivas para o campo da escola, bem como discutir, pesquisar e refletir sobre as resultantes de sua intervenção social, são fundamentais para que possamos constituir saberes que atendam às complexas realidades das escolas brasileiras. Hoje, mais do que em outro momento, observa-se que os saberes constitutivos da escola integram as diferentes dimensões históricas, culturais, estéticas e sociais, e a própria escolha dos conhecimentos a serem ensinados perpassam interesses, conflitos, buscas de legitimidade, disputas, etc.

O universo escolar parece ser o local do aprendizado apenas "formal", ou do conhecimento "sistematizado", mas, certamente, é um dos ambientes mais importantes de interação humana, e a dança deve ser considerada conhecimento integrador neste ambiente, bem como o mediador entre os diferentes saberes, não sendo apenas uma expressão teórica, prática, ou executora de técnicas. Desta forma, surgem possibilidades de estruturação de trabalhos transdisciplinares e que circulem qualitativamente entre e com outros saberes.

FIGUEIREDO, Valéria Maria Chaves de; PAIVA, Warla Giany. Reflexões sobre a disciplina de estágio curricular obrigatório I e II do curso de licenciatura em dança da UFG.

Revista da FUNDARTE, Montenegro, p.54-71, ano 19, no 37, Janeiro/Março.

Disponível em: http://.seer.fundarte.rs.gov.br/index.php/RevistadaFundarte/index> 30 de março de 2019. 


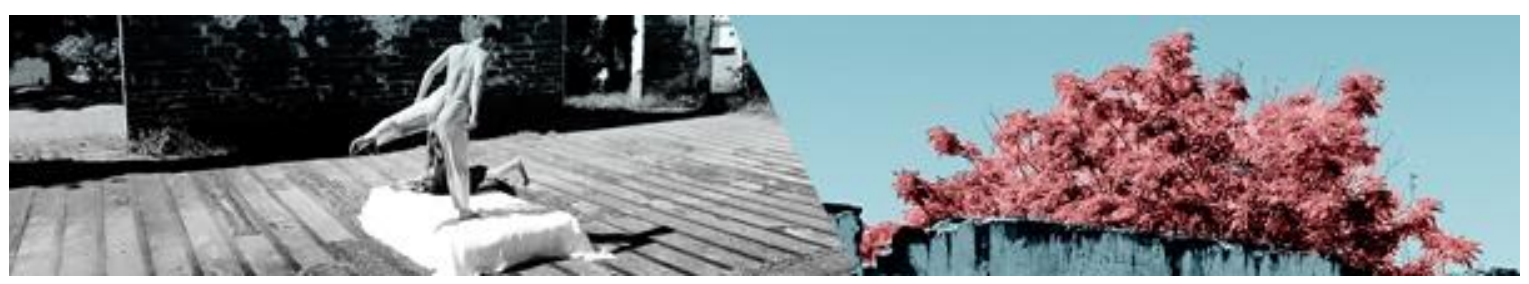

A dança ainda é vista apenas como possibilitadora da criatividade e da expressão humana, com ênfase nas suas qualidades didáticas e/ou nas condutas morais e de valores. Essa perspectiva reduz o seu real significado no contexto educacional. Pensar e refletir sobre a arte na nossa realidade, com certeza, permitiunos ampliar às muitas interpretações e significados para as subjetividades. Este é um dos papéis da arte e da educação: levar o estudante a construir significados e percepções junto às muitas realidades, dilatando a noção de cultura e a sua visão de mundo, criando, assim, uma maneira de o sujeito situar-se como indivíduo e ser atuante em sua própria história, consciente de que sua história individual foi e é construída pelas histórias e memórias de inúmeras outras pessoas, situações, contextos, crenças, valores e princípios.

Sabemos que a arte integra a cultura e que está em constante estado de ebulição, conflitos e superações. Isto possibilita a ampliação da produção e da ressignificação do conhecimento. Por isso, o desenvolvimento de projetos artísticopedagógicos é primordial para uma formação global, consistente, coletiva, democrática e que vise todas as áreas dos saberes. A contextualização dada pelos projetos pedagógicos é muito relevante no processo de construção do conhecimento, e a sua falta provoca a permanência de distâncias, às vezes insuperáveis, entre a arte e os contextos educacionais: em lugar de haver possibilidade e cooperação, prevalecem os distanciamentos e as práticas individualistas.

Para Veiga (2001), a questão dos projetos pedagógicos é um ponto de partida fundamental na educação, representa desafios em busca de novos caminhos para as escolas e estrutura os princípios e pressupostos a serem desenvolvidas, entre eles as questões entre a teoria, a prática e seus modos de fazer. A autora destaca duas concepções e dimensões de projetos: a primeira se expressa sob o ponto de vista estratégico e empresarial, que assume uma perspectiva autoritária, na qual a busca por qualidade e excelência está voltada para o mercado de trabalho, apenas tendo como palavras de ordem a eficiência e o custo; a segunda, na tentativa de superar uma visão conservadora, é o projeto emancipatório que aspira a uma gestão democrática,

FIGUEIREDO, Valéria Maria Chaves de; PAIVA, Warla Giany. Reflexões sobre a disciplina de estágio curricular obrigatório I e II do curso de licenciatura em dança da UFG.

Revista da FUNDARTE, Montenegro, p.54-71, ano 19, no 37, Janeiro/Março.

Disponível em: http://.seer.fundarte.rs.gov.br/index.php/RevistadaFundarte/index> 30 de março de 2019. 


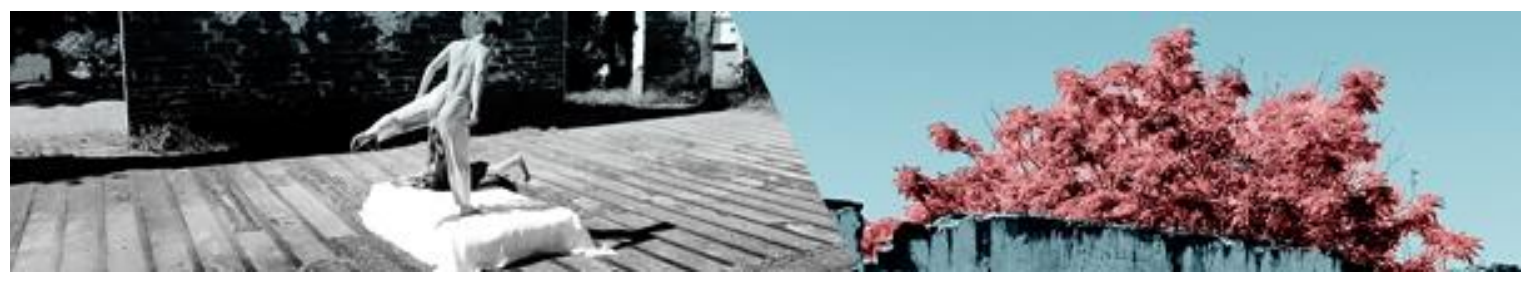

inclusiva, que combate o descaso, a despolitização e a exclusão, além de desencadear reflexões coletivas das realidades, em que as resultantes nascem dos conflitos apresentados, e que articula família, escola e comunidade em busca de consciência crítica e transformadora na esperança de uma escola melhor e para todos. Estas dimensões são fundamentais na construção das identidades dos sujeitos, nos processos educativos; e a dança deve ser parte atuante desta complexa engrenagem no campo da escola, estando conectada aos diversos modos e caminhos que possibilitem o conhecimento, a aprendizagem, uma participação ativa e transformadora das realidades.

\section{Tessituras em processo: experiências do estágio em dança da UFG}

A carreira do professor, assim como o contexto atual das licenciaturas associado à prática de ensino na educação básica, tem passado por um intenso processo de desvalorização. $O$ ensino das artes e, especificamente o ensino de dança, aventura-se atualmente por um novo momento de instabilidade, tendo em vista as mudanças curriculares propostas em nível federal, que giram em torno da saída das artes do Ensino Médio e das várias tensões existentes entre dança, educação física e artes construídas em torno da Base Nacional Curricular Comum (BNCC). Mesmo em um curso de licenciatura, o espaço voltado às disciplinas de âmbito pedagógico, como é o caso do bloco dos estágios, precisam ser continuamente afirmadas como legítimas e significativas à formação, tanto para os discentes como para os docentes. Tais problemáticas tornam relevantes iniciativas que se voltam para a sistematização e debate relativos à constituição das disciplinas, que compõe o núcleo dos estágios, no currículo dos cursos de licenciatura em dança, criados no país, nos últimos anos.

No caso do curso de dança da UFG, que iniciou suas atividades no ano de 2011, o estágio tem como pressuposto que:

A prática pedagógica é compreendida como expressão articulada da teoria com a realidade sócio-educacional, visando dinamizar os aspectos conceituais e a intervenção pedagógica no mundo real. Nesse sentido, o estágio curricular

FIGUEIREDO, Valéria Maria Chaves de; PAIVA, Warla Giany. Reflexões sobre a disciplina de estágio curricular obrigatório I e II do curso de licenciatura em dança da UFG.

Revista da FUNDARTE, Montenegro, p.54-71, ano 19, no 37, Janeiro/Março.

Disponível em: http://.seer.fundarte.rs.gov.br/index.php/RevistadaFundarte/index> 30 de março de 2019. 


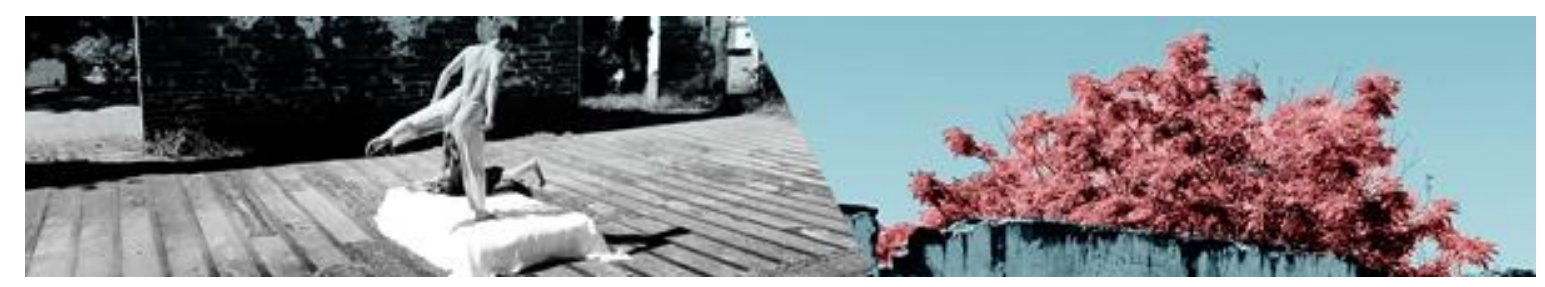

obrigatório configura-se como um espaço formativo e de preparação dos estudantes para 0 atendimento das necessidades humanas e sociais, preservando os valores éticos na educação básica e buscando a compreensão da realidade profissional à luz dos aportes teóricos estudados. Visa favorecer a reflexão sobre a realidade, a aquisição da autonomia intelectual e o desenvolvimento de habilidades relativas à profissão docente. Trata-se, portanto, de um componente curricular de carácter teórico-prático, cuja especificidade é proporcionar o contato efetivo do estudante com espaços educacionais, prioritariamente, a escola-campo - lócus do exercício profissional, envolvendo experiências em gestão, organização, planejamento, intervenção pedagógica, pesquisa e exercício da docência. (PPP, curso de Dança, UFG, p.47).

Diante de tais pressupostos, iniciou-se em 2013 a primeira disciplina de Estágio de um bloco de quatro disciplinas, tendo como caminho a ser percorrido, ao longo de dois anos letivos, a passagem por quatro etapas de fundamentação. Primeira: a apreensão da realidade da escola-campo, objetivando a compreensão, a descrição e a análise do cotidiano escolar. Segunda: a elaboração do projeto de ensino e pesquisa a partir da problematização das situações vivenciadas envolvendo preparação teórica, com atenção aos conhecimentos básicos de pesquisa, buscando o desenvolvimento de atitudes investigativas no estudante estagiário. Terceira: o desenvolvimento e execução da proposta de ensino e pesquisa na escola-campo. E quarta: a elaboração do relatório final de estágio com devolutiva à escola-campo e à comunidade acadêmica no formato de apresentação de seminários (PPP, Dança, UFG, p.49).

A proposta inicial implementada distribuía essas quatro disciplinas em dois campos de intervenção diferentes, sendo as disciplinas de Estágio Curricular Obrigatório I e III, responsáveis pela apreensão da realidade da escola-campo, por meio da observação e investigação da escola e suas práticas de gestão administrativa e pedagógica; enquanto os estágios II e IV eram voltados para a prática de ensino, ampliando a experiência docente dos estagiários.

Tal implementação foi provocadora de várias suspensões reflexivas, geradoras de adaptações na proposta inicial. Algumas das questões levantadas estavam na crítica realizada por parte dos estudantes e professores da disciplina, com relação ao formato muito parecido que delineava os dois agrupamentos. Outra questão importante estava

FIGUEIREDO, Valéria Maria Chaves de; PAIVA, Warla Giany. Reflexões sobre a disciplina de estágio curricular obrigatório I e II do curso de licenciatura em dança da UFG.

Revista da FUNDARTE, Montenegro, p.54-71, ano 19, no 37, Janeiro/Março.

Disponível em: http://.seer.fundarte.rs.gov.br/index.php/RevistadaFundarte/index> 30 de março de 2019. 


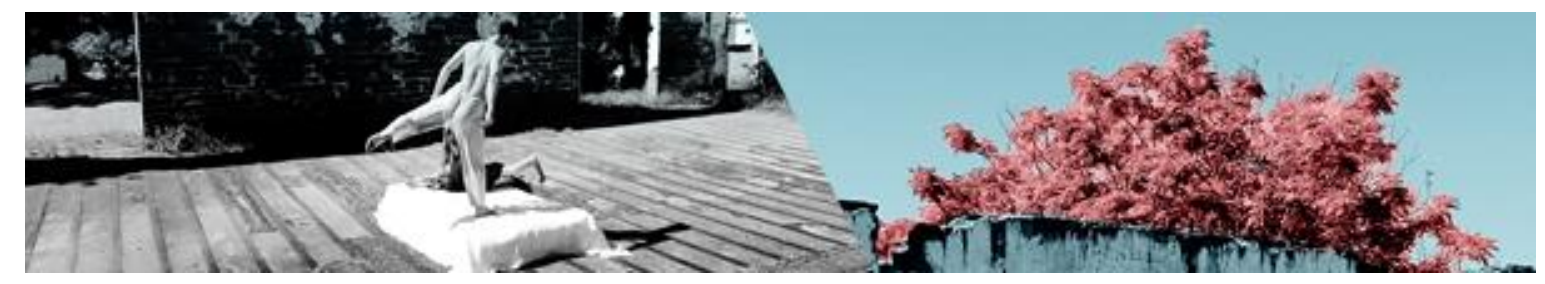

no fato de que o estágio III foi proposto como processo de investigação para uma futura regência, sendo que o estágio IV abria possibilidades de alteração de campo para instituições de ensino não formal, não dando continuidade ao estágio III. Sentia-se concretamente uma descontinuidade que fragmentava o conjunto dos estágios em dança.

Essas questões, discutidas no colegiado do curso após as primeiras experiências dos blocos das quatro disciplinas, provocaram mudanças significativas na estrutura e organização das mesmas. Essas passaram a vigorar, a partir de 2015, definindo-se que - Estágio I, responsável por abrir o bloco de disciplinas, com carga-horária maior, trataria de estudos teóricos mais amplos, relativos à organização geral da escola e da dança na escola, e se desenvolveria a partir de estudos investigativos. O estágio II se organizaria como continuidade do estágio I, resguardando, portanto, o mesmo campo de atuação, porém com foco na elaboração do projeto de ensino e na experiência da regência. Já os estágios III e IV se configurariam em campos diversificados e diferentes dos experimentados, mas também contendo momentos de observação e investigação, seguidos da regência; sendo o Estágio III, também no ensino formal e o estágio IV, podendo abarcar instituições de ensino de arte em ambiente não formal. Esclarecido algumas das mudanças ocorridas na estrutura geral dos nossos Estágios, lançaremos foco, a partir de agora, às questões mais especificas dos estágios I e II, respectivamente.

Partindo da proposta de ementa, o plano de ensino da disciplina, apresentado entre os anos de 2013 a 2016, propõe como objetivo geral "propiciar aos discentes o contato com o cotidiano escolar e sua estrutura". Para tanto, busca-se apresentar aos discentes as possibilidades de ensino e aprendizagem que tomem as experiências sociais como suporte de compreensão do mundo e da arte. O plano de ensino propõe, ainda, estudar possibilidades e especificidades para o ensino de dança em espaços formais, bem como compreender a organização do trabalho pedagógico e da gestão escolar e as suas implicações nos corpos e no ensino de dança, tendo como suporte 0 olhar crítico. A partir disso, é fomentado o debate crítico acerca do projeto político-

FIGUEIREDO, Valéria Maria Chaves de; PAIVA, Warla Giany. Reflexões sobre a disciplina de estágio curricular obrigatório I e II do curso de licenciatura em dança da UFG.

Revista da FUNDARTE, Montenegro, p.54-71, ano 19, no 37, Janeiro/Março.

Disponível em: http://.seer.fundarte.rs.gov.br/index.php/RevistadaFundarte/index> 30 de março de 2019. 


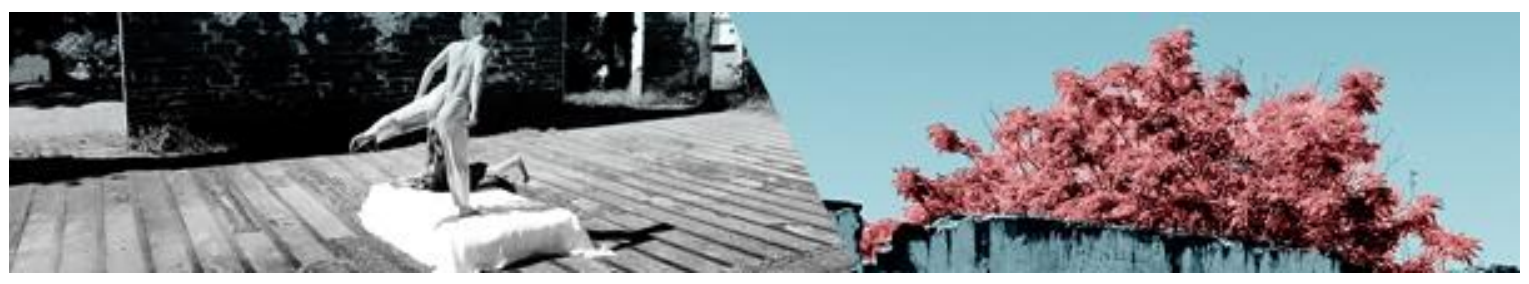

pedagógico, currículo e avaliação no ambiente escolar de educação básica, preferencialmente na rede pública de ensino, e suas implicações no campo da arte (plano de ensino da disciplina estágio I).

Para execução desses objetivos, a disciplina foi organizada em quatro unidades geradoras, ancoradas em debates e discussões: por meio de seminários em torno das teorias pedagógicas e da organização do trabalho escolar, tendo como referência textos de Paulo Freire (1996), Demerval Saviani (1991) e Sueli Mendonça (2011); a contextualização do trabalho pedagógico e o ensino de dança na escola a partir das reflexões tecidas por Márcia Strazzacappa (2006) e Isabel Marques (2010); o Projeto político-pedagógico, debatido juntamente com as pesquisas de Ilma Passos (2002) e Marília Fonseca (2003); e o currículo para o ensino de dança, subsidiado pelos estudos de Karenine Porpino (2012), entre outros; entrelaçando, assim, as discussões em torno da gestão, espaço escolar e possibilidades pedagógicas para o ensino de dança.

Paralelo a tais debates e reflexões propostas para construir uma possível pesquisa, na qual os estagiários iriam a campo, elegemos os estudos de Mirian Goldenberg em A Arte de Pesquisar (2004 8a edição), bem como a retomada dos estudos de sociocoreologia, desenvolvidos por Regina Miranda, no intuito de analisar 0 cotidiano escolar a partir de conceitos da dança. Buscamos, com isso, desenvolver o estudo investigativo de problemáticas significativas da organização geral da escola e da dança.

O intuito da pesquisa era potencializar a atitude investigativa dos estagiários no campo. Mediante a necessidade de ampliação de tais compreensões, adotou-se também o texto Etnografia da prática escolar, de Marli André (1995). Após estudo e levantamento de várias questões possíveis de se presentificarem no campo de estágio, dá-se início às idas a campo. Tal enfrentamento coloca toda a estrutura do estágio à prova, haja vista que a organização da instituição campo, assim como da instituição universitária se constrói em meio a um campo de tensões, de fato um campo de batalhas hercúleas.

FIGUEIREDO, Valéria Maria Chaves de; PAIVA, Warla Giany. Reflexões sobre a disciplina de estágio curricular obrigatório I e II do curso de licenciatura em dança da UFG.

Revista da FUNDARTE, Montenegro, p.54-71, ano 19, no 37, Janeiro/Março.

Disponível em: http://.seer.fundarte.rs.gov.br/index.php/RevistadaFundarte/index> 30 de março de 2019. 


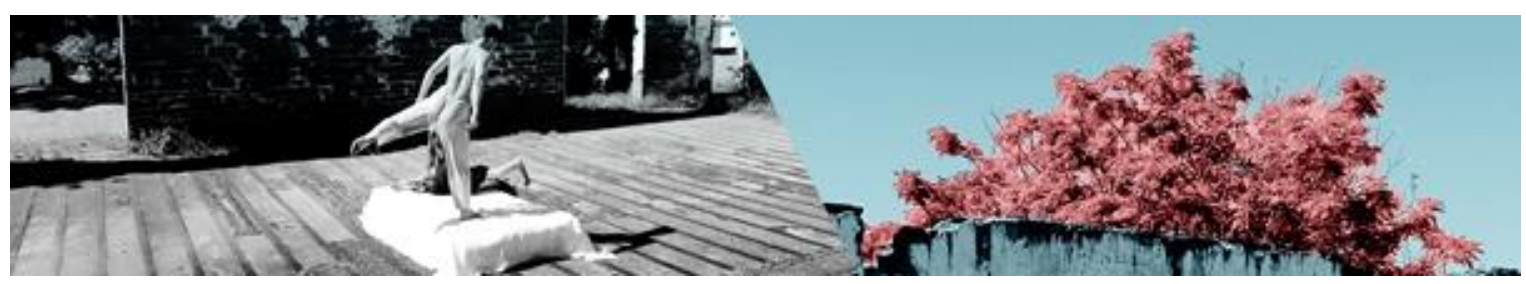

Uma gama de questões delicadas vai se estabelecendo nos entremeios das relações que compõem as várias camadas constituidoras do estágio. No bojo destas estão os agentes principais: estagiários, professores, supervisores, orientadores e coordenadores de estágio; tencionando-se e acolhendo-se, e (re)construindo, a cada campo, relações únicas ao questionar qual é o papel de cada um na construção e reconstrução do que é tangível e intangível na prática/presença pedagógica ${ }^{3}$. E isso é algo que se complexifica ainda mais no estágio II e nos estágios subsequentes, frente à necessidade de criação de espaços para a regência dos estagiários.

Estágio Curricular Obrigatório II se configura por ser um momento, no qual o estagiário terá como desafio 0 :

Planejamento, construção, implementação e avaliação de proposta de ensino de dança em escolas da rede pública de ensino podendo contemplar Educação Infantil, Ensino Fundamental, Ensino Médio, Educação de Jovens e Adultos, Educação Indígena e Educação Especial. (EMENTA, PROJETOS PEDAGÓGICO, CURSO DE DANÇA, UFG, 2011).

Para o desenvolvimento do estágio II, é sugerida aos estudantes a retomada dos estudos realizados, no curso, sobre a prática pedagógico-metodológica em dança; trata-se de um convite para a reaproximação das disciplinas ministradas anteriormente ou paralelamente a este estágio. Para além desta retomada busca-se dialogar com alguns autores de referência para a didática e a prática de ensino em âmbito geral e específico. Entre estes está dissertação defendida por Luís Carlos de Freitas sobre a organização do trabalho pedagógico e o material audiovisual produzido pelo Salto para o Futuro, que trata da temática dança e educação.

Esses estudos juntaram-se aos debates sobre possíveis caminhos para a elaboração das propostas de ensino e pesquisa, amparando-se no estágio I, visando o retorno ao campo. Este se deu inicialmente, no intuito de perceber a configuração do segundo semestre na escola-campo e, em um segundo momento, buscou incentivar o diálogo entre estagiários e professores supervisores, com o intuito de delinear as

\footnotetext{
3 Termo adotado pelo Projeto de Educação da Arte do Bem Viver, pelo Instituto de Pesquisa e Extensão em Artes Educação e Tecnologias Sustentáveis - IPEARTES / SEDUC-Go.
}

FIGUEIREDO, Valéria Maria Chaves de; PAIVA, Warla Giany. Reflexões sobre a disciplina de estágio curricular obrigatório I e II do curso de licenciatura em dança da UFG.

Revista da FUNDARTE, Montenegro, p.54-71, ano 19, no 37, Janeiro/Março.

Disponível em: http://.seer.fundarte.rs.gov.br/index.php/RevistadaFundarte/index> 30 de março de 2019. 


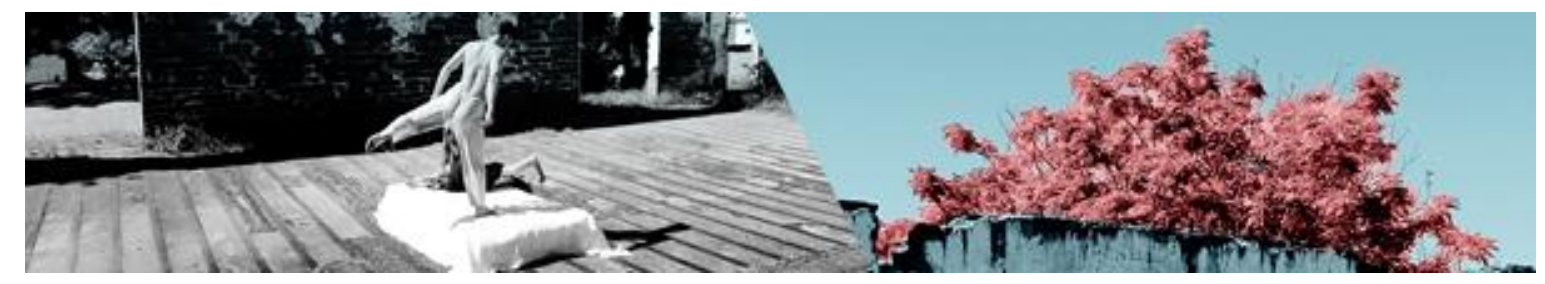

margens da construção dos planos de ensino dos estagiários, para a organização da futura experiência da regência.

Um dos momentos de atenção no estágio II está na necessidade dos estagiários proporem ações articuladas com as proposições lançadas pelo professor supervisor para o semestre, que em geral possuem como deliberação a necessidade de encerrar a ação pedagógica com uma apresentação artística de final de ano; algo que se torna bastante complexo, tendo em vista que o estagiário inicia o campo após o início do semestre e encerra o mesmo antes da finalização do semestre. Ou seja, o tempo para o desenvolvimento de um processo de criação, composição e apresentação artística é bastante restrito, tendo em vista que as atividades de estágio e, muitas vezes, as aulas de dança, acontecem uma vez na semana. Mesmo quando as aulas se desdobram em mais dias na semana, a articulação entre professores supervisores e estagiários precisam acontecer de forma muito aproximada e articulada, para que viabilize a realização do que foi proposto no semestre aos estudantes da escola e à escola. O não alcance de tais objetivos é gerador de um fluxo de frustrações que podem desestabilizar a relação de estágio entre instituição-campo e curso de dança.

\section{No Campo: Experiências, Processos e Transformações}

O campo de estágio é um lugar muito especial, pois carrega em suas peculiaridades uma grande riqueza de aprendizados. Dentro dessa multiplicidade está a ação de aproximar, dos estudantes da educação básica, as experiências aprendidas e traduzidas pelos licenciados, por metodologias, propostas pedagógicas e artísticas; processos de ensino e aprendizagem que façam sentido e significado aos estudantes.

Diante dos desafios do processo de tradução, os alunos propuseram, entre 2015 e 2016, ações atravessadas pelos saberes em dança aprendidos na universidade, tais como: jogo coreográfico, jogos de improvisação e composição propostos pela disciplina Improvisação e Composição; o inventário pessoal proposto pela disciplina Metodologia do Ensino de Dança II; processos de criação tendo como paramentos a investigação,

FIGUEIREDO, Valéria Maria Chaves de; PAIVA, Warla Giany. Reflexões sobre a disciplina de estágio curricular obrigatório I e II do curso de licenciatura em dança da UFG.

Revista da FUNDARTE, Montenegro, p.54-71, ano 19, no 37, Janeiro/Março.

Disponível em: http://.seer.fundarte.rs.gov.br/index.php/RevistadaFundarte/index> 30 de março de 2019. 


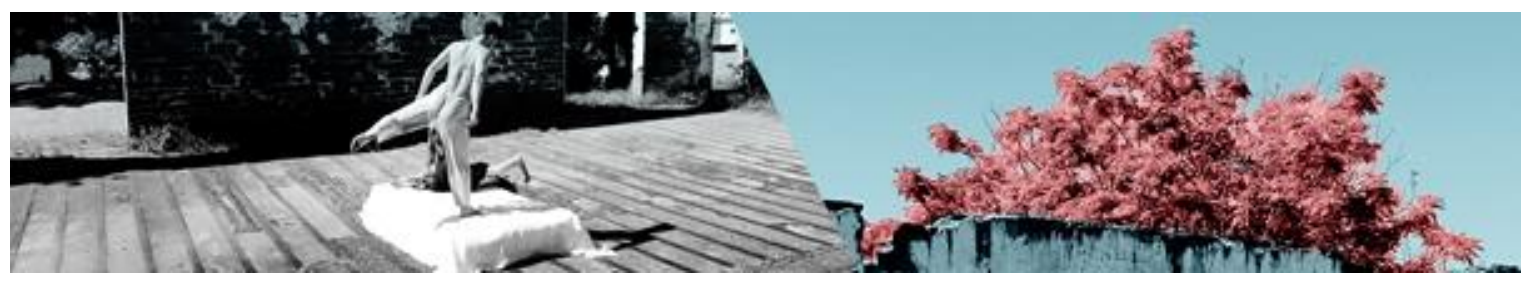

experimentação e improvisação de movimento; propostas presentes nas disciplinas de Ateliê de Criação; bem como os repertórios de dança da formação pessoal das estagiárias e estagiários, como o das danças urbanas, um repertório bastante presente nesse período.

Quanto às metodologias, há uma busca pela a articulação da teoria com a prática, assim como se percebe também a tentativa de transbordar as propostas que se fixam apenas na mimese de movimentos de forma alienada e/ou descontextualizada. Como se dá a construção da autonomia do estagiário e da estagiária no estágio? E como essa autonomia reverbera nas propostas artístico-pedagógicas desenvolvidas por eles e elas no campo de estágio?

Há uma gama de sutilezas que compõem a trama do estágio. Esse se faz de encontros dançantes entre coordenadores e coordenadoras do estágio, professor ou professora supervisor(a) do estágio na escola, estagiárias e estagiários, estudantes da educação básica, equipe gestora da escola-campo e pais dos e das estudantes; uma trama de possibilidades infinitas que, em determinadas circunstâncias, se embaraçam.

No caso dos estagiários, estes se veem diante de um grande desafio. Por vezes, reafirmam para si mesmos e para o coletivo que não atuarão profissionalmente com a dança na escola, algo que gera inicialmente grandes desconfortos e insatisfações no momento de cursar o núcleo dos estágios. Alguns receosos e inseguros por não saberem como o trabalho vai acontecer, por não terem tido experiências anteriores com a docência; outros, ao contrário, afirmam-se já sabedores do que vai acontecer, e, por isso, não se comprometem com os encaminhamentos propostos. É uma mistura de percepções, emoções, incertezas, certezas e julgamentos. Com a necessária aproximação dos estudantes estagiários, o professor supervisor e os estudantes do ensino básico, toda essa trama, vai ganhando novas formas, preenchimentos e contornos. Aqueles que antes se mostravam resistentes percebem o momento como de grande potencial criativo, inventivo e instigador de novos modos de fazer e pensar; os que se apresentavam com insegurança, percebem-se mais seguros e ousados; e os que se colocaram como os que já sabem tudo, descobrem que cada experiência em

FIGUEIREDO, Valéria Maria Chaves de; PAIVA, Warla Giany. Reflexões sobre a disciplina de estágio curricular obrigatório I e II do curso de licenciatura em dança da UFG.

Revista da FUNDARTE, Montenegro, p.54-71, ano 19, № 37, Janeiro/Março.

Disponível em: http://.seer.fundarte.rs.gov.br/index.php/RevistadaFundarte/index> 30 de março de 2019. 


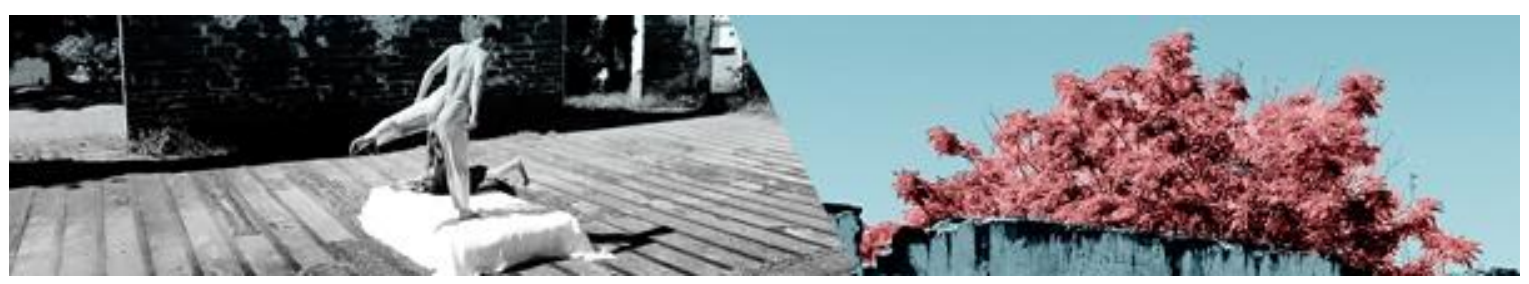

docência é única e ali se coloca em cheque todo conjunto de saberes que adquirimos ao longo da vida. Isso tem demonstrado que o núcleo dos estágios, no curso de dança, provoca e exigem uma dinâmica contínua de transformação, reflexão e reinvenção.

\section{Considerando}

A arte é educadora enquanto arte e não enquanto arte educadora.

Walter Benjamin.

Os territórios de intervenção da dança são inúmeros, e não podemos nos "desresponsabilizar" de escolhas e decisões criteriosas. Uma mudança, de fato, não pode ser fatalista ou imediatista. Importam, sim, os projetos pedagógicos e sua dimensão na constituição de identidades, a importância da formação, as melhorias na qualidade de trabalho, a discussão da valorização da área, a participação qualitativa e ativa nos processos da escola, as equidades entre os saberes, o entendimento dos lugares formativos, as diferentes interfaces entre escola e comunidade, as políticas educacionais, os currículos, os processos de avaliação, comunicação e interação nos ambientes educativos; enfim, são muitos os desafios que emergem a partir da escola e nos conectam com as realidades e suas problemáticas.

Sonia Kramer (1998) pergunta: “O que é básico na educação básica?” E enfatiza que a escola básica deve se comprometer, principalmente, com a cidadania e a democracia, e, para tal, a formação cultural é um dos elementos básicos: "se falei de água para falar de cidadania, quero falar de cultura como do ar que respiramos". (KRAMER, 1998, p. 14). Também defende a força do conhecimento como força de sustentação daquilo que nos é coletivo:

Defendo a ideia de que é básico que a escola, as crianças, os jovens e os adultos recuperem, aprendam, descubram a paixão pelo conhecimento, porque só o ser humano pode conhecer e, neste processo - de construção de conhecimento - , o papel do outro e da coletividade é fundamental. (KRAMER, 1998, p. 20).

FIGUEIREDO, Valéria Maria Chaves de; PAIVA, Warla Giany. Reflexões sobre a disciplina de estágio curricular obrigatório I e II do curso de licenciatura em dança da UFG.

Revista da FUNDARTE, Montenegro, p.54-71, ano 19, no 37, Janeiro/Março.

Disponível em: http://.seer.fundarte.rs.gov.br/index.php/RevistadaFundarte/index> 30 de março de 2019. 


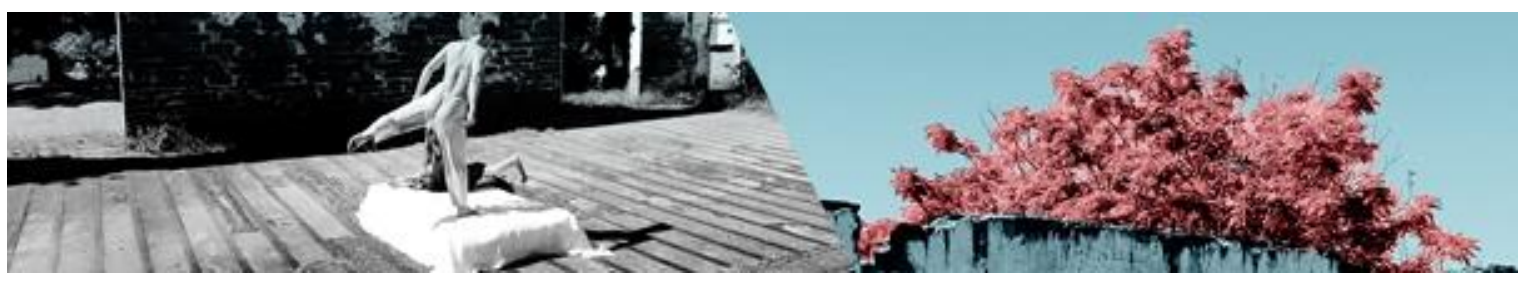

Por fim, a escola básica é elemento fundamental na vida cultural, social e política das pessoas. Assim, os saberes científicos e artísticos são direitos de todos, são conhecimentos a serem apropriados e incorporados à vida; e a articulação dos saberes são experiências a se constituírem na formação humana. Vale acentuar que a dança deve, por mais pesado e difícil que seja o cotidiano das escolas na realidade brasileira, conquistar responsabilidades via formação qualificada, produção de conhecimentos e reflexões sistemáticas e críticas da área.

$\mathrm{Na}$ escola onde acompanhamos a disciplina Dança, nossa relação com a professora regente trouxe importantes problematizações para se compreender sustentações teóricas e práticas e suas relações ao projeto pedagógico. Durante o estágio, ficou evidente a constituição das diversas relações da dança com a escola e a comunidade e a enorme complexidade para atender aos princípios da inclusão, dentre elas: o não apagamento das diferenças e das diversidades sociais e culturais dos estudantes; a valorização das singularidades que emergiram junto com as pluralidades técnicas e metodológicas propostas pela professora; e os vários modos de ensinar como fundamento para o ensino da dança na escola. Isso tudo garantiu distender e rever as dicotomias entre prática e teoria e atender as diferentes necessidades educativas dos estudantes. O não empobrecimento dos conteúdos por distanciamentos do projeto pedagógico, com valiosa percepção de circularidade e aberturas para as áreas disciplinares, bem como as que não são disciplinares, e que prioriza a ideia de uma não neutralidade e se distancia da ideia de transmissão de conhecimento instrumental e unilateral, estão presentes, ainda, na escola e no campo da arte.

A formação deste aluno crítico, criativo, consciente, cidadão, participativo e sujeito deve fortemente ser confrontada com a ideia de um professor de dança alienado, passivo, ocioso, despolitizado e tecnicista. O "oficio de mestre", em síntese, enfrenta as tensões e os muitos conflitos do mundo que nos cerca, e não há como fugir, mas, como destacou Arroyo (2000, p. 83), nossa docência será sempre uma humana

FIGUEIREDO, Valéria Maria Chaves de; PAIVA, Warla Giany. Reflexões sobre a disciplina de estágio curricular obrigatório I e II do curso de licenciatura em dança da UFG.

Revista da FUNDARTE, Montenegro, p.54-71, ano 19, no 37, Janeiro/Março.

Disponível em: http://.seer.fundarte.rs.gov.br/index.php/RevistadaFundarte/index> 30 de março de 2019. 


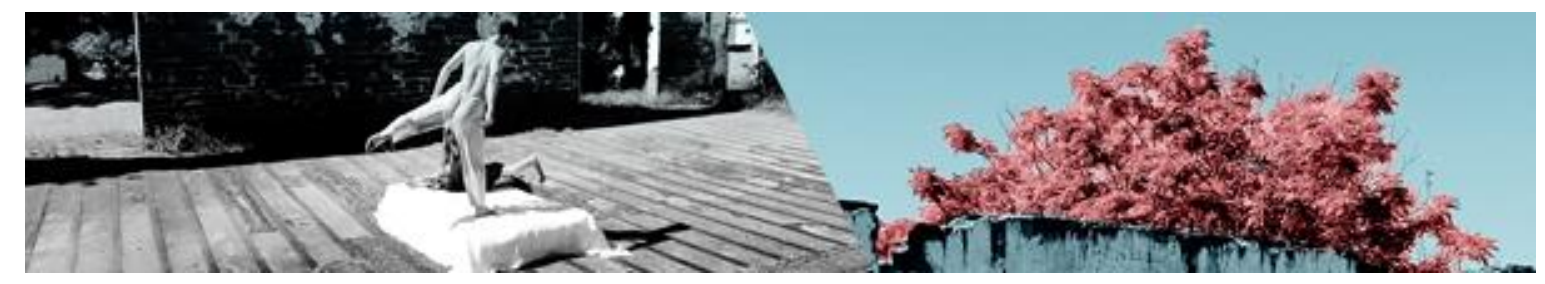

docência e o professor de dança deve ser parte deste sentido, onde o educar é, acima de tudo, humanizar.

\section{Referências:}

ARROYO, Miguel. Ofício de mestre: imagens e autoimagem. Petrópolis: Vozes, 2000. 10, mai. 1988.

Miguel. O direito ao tempo de escola. Cadernos de Pesquisa, n. 65, p. 30-

BARBOSA, Ana Mae. John Dewey e o ensino da arte no Brasil. São Paulo: Cortez, 2002.

FERRAZ, Maria Heloisa Correa; FUSARI, Maria Felisminda de Rezende. Arte na educação escolar. 4. ed. São Paulo: Cortez, 2010.

FERREIRA, Sueli (org). O ensino das artes: construindo caminhos. Campinas SP: Papirus, 2001.

FIGUEIREDO, Marcio. A corporeidade na escola: análise de brincadeiras, jogos e desenhos de crianças. Porto Alegre: Educação e Realidade, 1991.

FREIRE, Paulo. Pedagogia da autonomia. São Paulo: Vozes, 1980.

KRAMER, Sonia. Infância e produção cultural. Campinas: Papirus, 1998.

OSINSKI, Dulce. Arte, história e ensino: uma trajetória. São Paulo: Cortez, 2001.

PORPINO, K. O. . Dança e Currículo. Salto para o Futuro , v. XXII, p. 9-15, 2012.

PORPINO, K. O. ; ALMEIDA, M. C. X. ; NÓBREGA, T. P. . Dança é Educação: interfaces entre corporeidade e estética. Diálogos Possíveis (FSBA), Salvador-BA, v. 1, p. 221-227, 2003.

READ, H. A educação pela arte. São Paulo: Martins Fontes, 1982.

SAVIANI, Demerval. Educação: do senso comum à consciência filosófica. São Paulo: Cortez, 1989.

VEIGA, IIma Passos Alencastro. As dimensões do projeto político-pedagógico. São Paulo: Papirus, 2001.

FIGUEIREDO, Valéria Maria Chaves de; PAIVA, Warla Giany. Reflexões sobre a disciplina de estágio curricular obrigatório I e II do curso de licenciatura em dança da UFG.

Revista da FUNDARTE, Montenegro, p.54-71, ano 19, № 37, Janeiro/Março.

Disponível em: http://.seer.fundarte.rs.gov.br/index.php/RevistadaFundarte/index> 30 de março de 2019. 